\title{
Aanbid die godsdienste dieselfde God?
}

J Buitendag

Universiteit van Pretoria

\begin{abstract}
Do all religions pray to the same God?

A highly debated matter in South African religopolitical field is the question of whether different religions may worship together and if they pray to the same god at all. This question has come to the fore during the negotiation phase for a new governmental dispensation in this country, as well as in the opening prayers for Parliament in a pluralistic society. An exposition of the different views is given. The author opts for a view of existential experience of the personal, revealed, One and Only God. This conviction gives us the confidence in the Gospel so indispensable to the life of our churches in a pluralistic context. The dichotomy between subjectivity and objectivity is being rejected as is the consequent attitude of timidity or of anxiety on the part of the Christians in South Africa. A distinction should be made between worship in the church and prayers in $a$ worldly situation.
\end{abstract}

\section{INLEIDING}

Indien mens die vraag van die opskrif oordink, besef mens dat daar logies gesproke net twee moontlike antwoorde hierop gegee kan word: Ja of nee. Tog is die werklikheid nie so skakeringloos nie. Elkeen van hierdie twee moontlike antwoorde het ook fynere nuanses. Indien ons sê ja, die godsdienste aanbid wel dieselfde God, lyk my is daar minstens ook twee moontlikhede in hierdie kategorie, te wete 'n standpunt van sinkretisme of 'n standpunt van pluralisme. Indien ons sê nee, die godsdienste aanbid nie dieselfde God nie, moet ons ook met twee moontlikhede rekening hou. Die Christendom kan dan of absoluut/polemies ten opsigte die ander godsdienste staan of tangensieel/indifferent.

Ons het dus twee kategorie met twee moontlikhede elk. Ek wil nou elkeen van die vier moontlikhede kortliks aan die orde stel. Ten slotte beweeg ons dan na die praktyk toe waaruit hierdie vraag se aktualiteit vandag ontstaan het. Dit word gedoen by wyse van die trek van enkele prinsipiële riglyne wat die debat ook kan stimuleer. 
Alvorens ons egter hiermee kan begin, is dit nodig om 'n enkele oriënteringspunt aan te dui, naamlik die mens se subjektiewe vertrekpunt, oftwel religieuse grondervaring, in 'n saak soos hierdie. Min mense pretendeer vandag nog om 'n kliniese objektiwiteit in die verstaan van die werklikheid na te hou. In die baie lesenswaardige boek van Lesslie Newbigin (1989:20) stel hy hierdie waarheid soos volg: 'But the rationality of the universe is not something that science can prove; it has to be assumed as the starting point of scientific effort, and the assumption is a faith-commitment'. Dit beteken dus dat hierdie vraag as Christen-gelowige op 'n gesistematiseerde wyse probeer beantwoord word. Met ander woorde, ek kan nie koud-rasioneel na die verskillende godsdienste gaan kyk, en dan op grond van sintuiglike waarneming, vir die Christendom kies nie. Dit bly daarom altyd 'n geloofskeuse. Ek kan nie anders oor God praat as vanuit my persoonlike relasie tot Hom nie. Dit maak my dus partydig. Om van 'n absolute God, 'n Gott-an-sich, te praat, is geen teologiese aangeleentheid nie, maar wel 'n filosofiese. Die vraag van die opskrif word dus in hierdie referaat vanuit 'n bepaalde ontmoetings-gebeure hanteer.

Maar hiermee hang ook 'n tweede probleem saam, naamlik die spreke oor die onsigbare God. Bonhoeffer $(1982: 12,16)$ het gesê ons moet in die eerste plek die wie-vraag in die geloof hanteer, en nie die wat-vraag nie. Maar hoe word die onsigbare nou gesê, of dan onder woorde gebring? Hoe word die absolute in relatiewe terme uitgedruk? Dit is hier waar die voorlopigheid van ons spreke na vore kom. Die tradisionele antwoorde van antropomorfistiese uitsprake oor God soos die theologia negativa word slegs gesê wat God menslikerwyse nie is nie. Die via eminentiae weer in die superlatief, slegs die volmaaktheid word by gewoon menslike eienskappe gevoeg.

Ons kan in hierdie verhouding slegs by wyse van simbole, of dan metafories, oor God praat. Hierdie nie-empiriese en primêre ervaring van die teenwoordigheid van God in my lewe, kan alleen analogies uitgedruk word. Natuurlik getuig die Heilige Gees saam met ons gees hierin (testimonium internum Spiritus Sancti), maar juis dit maak dit persoonlik en daarom relatief. Of kom ek probeer my beter uitdruk: wie nie met God praat nie, kan ook nie oor Hom praat nie. En hierdie spreke met God ag ek as die voorveronderstelling vir hierdie debat. Hierby moet ook verstaan word dat sodanige spreke moontlik is omdat God Hom persoonlik tot ons wend en dat hierdie geloofsapriori ten grondslag lê. Dit is waarom Newbigin (1989:80-89) die uitverkiesing hier gekwalifiseerd ter sprake wil maak.

Vervolgens kan ons nou na die twee kategorieë van antwoorde kyk, elk met sy eie twee variasies. 


\section{DIE GODSDIENSTE AANBID WEL DIESELFDE GOD}

\subsection{Sinkretisme}

Oorspronklik was sinkretisme 'n politieke term. Plutarchus beskrywe die Kretense se betrokkenheid met die vyand as 'n synkretismos (Pannenberg 1979:268). Mens moet egter versigtig wees om nie die Nuwe Testamentiese skrywers se aanwending van filosofiese begrippe soos, gnosis, logos, pleroma, mysterion, en andere as sinkretisme aan te dui nie. Afgesien daarvan dat daar semantiese verskille hiertussen bestaan het, was dit die begrippe van die tyd en is die evangelie aan die mense destyds hierdeur gekommunikeer.

Daar word twee vorms van sinkretisme onderskei, naamlik die overte vorm en die primitiewe vorm (Henry 1973:656). Eersgenoemde is 'n bewustelike en sistematiese poging om verskillende en selfs weersprekende elemente van godsdienste te versoen. Manicheïme en Mitraïsme, albei Persiese godsdienste, sou as voorbeelde hiervan kon geld. Sedert die Verligting het hierdie siening egter in die Christendom sterker na vore gekom, byvoorbeeld Lessing se poging van die drie ringe en ook Aquinas se verstaan van die implisiete geloof. Erasmus se poging om die Christelike dogma tot ' $n$ absolute minimum te reduseer en Servet se verwerping van die Triniteitsleer, het dieselfde intensie (Galling 1961:1062).

Die poging van Helena Petrofna Blavatsky se Teosofiese Vereniging wat in 1875 in die VSA gestig is, het op dieselfde noot voortgegaan. Veral die Hindoeime het hier as fondament gefigureer, maar die Bahai van Islam en talle sektes soos die Oomota en Ittoen van die Sjintoeïme en die Boeddhisme het ook hulle plek hierin gevind. Die resente werke van Fritjof Capra (die briljante oud-hippie met die Ph D in Fisika) het ook sulke pogings aangewend. In sy boek, The Tao of physics, poog hy juis om die Oosterse mistisisme met moderne fisika te versoen. Onder die opskrif van overte sinkretisme, sou mens ook sekere van die onafhanklike Swart Kerke van Afrika kon plaas wat die Christendom met 'n Afrika spiritisme verenig.

Tweedens is daar die primitiewe of spontane sinkretisme. Hierdie is eerder 'n gesindheids- of bewussyns-aangeleentheid as 'n sistematiese een. Die New Age se holistiese uitgangspunt sou hieronder verstaan kon word. Die mens moet evoluerend partisipeer aan die groter geheel om in die $\mathrm{Al}$ opgeneem te word.

\subsection{Pluralisme}

Hierdie is maar 'n geringe variasie op bogenoemde sinkretistiese uitgangspunt. Mens sou dit dalk die relatiwistiese benadering kon noem. Die komponent wat egter nie uit die oog verloor moet word nie, is die sinergistiese dimensie wat wil se dat die waarheid meer is as die somtotaal van die dele. 
Dit beteken dat godsdienste onderling baie by mekaar te leer het. Sending beteken dan nie om die ander oor te haal nie, maar om te luister en te leer.

Dit is duidelik dat ons hier met 'n relatiwisme, wat eie aan sekularisme is, te doen het. Godsdiensgelykheid word soos 'n kosbare kleinnood bewaar. Per definisie is dit ook nie nodig om te kies nie, sê voorstanders hiervan, omdat alle paaie tog by Rome eindig.

In sy Schriften zur Theologie, Band $V$, sluit Karl Rahner (1962:136-158) by hierdie standpunt aan, alhoewel met 'n voorrangsposisie aan die Christendom. Hy vertrek vanaf die Selfmeedeling van God aan alle mense wat 'n bonatuurlike eksistensiale ervaring tot gevolg het. Alleen so kom die ware mens na vore. Dit hoef egter nie eksplisiet of reflektief te geskied nie, maar is ook anoniem. Mens sal dus kan sê dat hierdie gebeure die mens tot volle selfontplooiing lei. Derhalwe is Christus dan die volle Selfmeedeling van God. In Hom is die bonatuurlike eksistensiaal finaal en onherroeplik meegedeel. Hieruit kan Rahner nou vier stellings stel:

- die Christendom verstaan homself as die eintlike godsdiens;

* ander godsdienste het nietemin bonatuurlike waarheidselemente en is daarom 'legitieme religie';

- die verhouding van die Christen teenoor aanhangers van ander godsdienste is dus geensins asof teenoor nie-Christene nie, maar teenoor bloot 'anonieme Christene'; en

- God is groter en meer as die mense en die kerk. Sy genade is ook op verborge wyse aanwesig in die anonieme Christendom. Dit vra egter om geëkspliseer te word.

Hans Küng het daarop gewys dat hierdie standpunt van Rahner eintlik onbevredigend is. Ten diepste tree dit vanuit 'n meerderwaardigheid teenoor ander godsdienste op, alhoewel dit juis erkenning daaraan wil verleen (Küng 1991:236).

Eintlik het mens in hierdie antwoord met 'n onoorkombare probleem te make. As alle paaie na Rome lei, bring een pad jou nie eerder daar uit nie. Die Christendom se etiek en antropologie byvoorbeeld gee aan hom geen voorrangposisie nie. Daarom bly ons by ons standpunt: 'n Keuse vir die Christendom is dus 'n geloofskeuse en dit hef die relativisme op. Die paradoksale uitspraak kan dus hier gemaak word dat relativisme slegs iets sê solank dit niks sê nie. Die oomblik as dit iets sê, hef dit sigself op en sê dus niks!

Voordat ons egter oorgaan na die tweede kategorie van 'n moontlike antwoord, naamlik dat die godsdienste nie dieselfde God aanbid nie, is dit nodig om terloops by te voeg dat die teologie van die Rooms Katolieke Kerk sedert Vaticanum II aansluit by hierdie alle-paaie-lei-na-Rome-standpunt. In sy Verklaring oor die nieChristelike godsdienste word gesê: 'The Catholic religion rejects nothing of what is 
true and holy in these religions' (Küng 1975:738). Die Wêreldraad van Kerke het selfs (nog) nie sover gegaan nie. Nóg in sy Guidelines for dialogue with individuals of different religions and ideologies (1979), nóg in sy gesamentlike sitting in Vancouver (1983), is die vraag na die heil buite die Christelike kerke beantwoord.

\section{DIE GODSDIENSTE AANBID NIE DIESELFDE GOD NIE}

\subsection{Absoluut en polemies}

Hier word gesê dat godsdienste as sodanig, sonde is. Dit is suiwer menslike projeksies en verlangens van onder af. God openbaar sy oordeel oor die mensdom en die Christelike geloof antwoord hierop gehoorsaam en afhanklik. Die Christendom is dan die openbaring van God van bo. Kom ons kyk nou na 'n paar pogings in hierdie opsig.

Die Vierde Lateraanse Konsilie (1215) se definisie is welbekend: extra ecclesiam nulla salus. Die ekumeniese vergadering by Florence (1442) het ook bevestig dat niemand buite die RKK, nie heiden, Jood, afgedwaalde, deel het aan die ewige lewe nie, maar bestem is vir die hel. Ons het egter reeds gesien dat hierdie uitspraak deur Vaticanum II vervang is.

Karl Barth onderskei tussen openbaring en religie soos van bo en van onder. Feuerbach se kritiek het dan slegs op laasgenoemde betrekking. Religie is vir hom aan ongeloof gelyk. Daarom moet religie teologies vanuit die openbaring van God verstaan word, en wel in die sin dat dit die religie ophef (Barth 1959:357). In plaas van luister, praat die mens in religie en gryp hy na God. Daarom is hierdie gryp 'n vergryp en kom dus teenoor openbaring te staan (Barth 1959:330). Daar is egter net een ware religie en dit is die Christendom (Barth 1959:357), omdat slegs hierbinne die Goddelose geregverdig word. Dit is die raamwerk, die Pniël van Genesis 32, waar die mens voor God staan. Die Christelike godsdiens is nou die predikaat van die Subjek, naamlik van die Naam Jesus Christus (Barth 1959:381). Ons het nie Hom gekies nie, maar Hy kies ons.

\subsection{Tangensieel en indifferent}

Hierdie standpunt lyk op die oog af dieselfde as die tweede moontlikheid van die eerste kategorie (bv Rahner se standpunt), maar verskil tog daarin dat daar ja! op die vraag of alle godsdienste dieselfde God aanbid, geantwoord word. Ons moet dus die indifferensie nie so verstaan dat die Drie-enige God maar net een van baie name is nie, nog erger, Een van baie gode is nie. Nee, Hy is die ware God. Maar dit word egter nie kwetsend en aanmatigend gedoen nie en daar word erken dat die ander godsdienste daar is en dus naasmekaar (tangensieel) bestaan. Op gewoon 
godsdiens-fenomenologiese vlak is die Christendom dan een van baie (Küng 1980:88) - maar op geloofsvlak is die keuse vir die God gemaak van Wie geglo word dat Hy die Waaragtige is.

In sy boek, Theology for the third millennium, handel Hans Küng breedvoerig oor hierdie problematiek. Hy stel die volgende drie punte as die gesindheid van die Christendom teenoor ander godsdienste.

- indifferensie in plaas van die indifferentisme van die ortodoksisme wat homself as die enigste maatstaf vir waarheid sien en sy standpunt op ander afforseer;

- relatiwiteit in plaas van 'n relativisme wat 'n kreatiewe naasbestaan van verskillende godsdienste verhinder; en

- sintese in plaas van sinkretisme wat alles saamgooi (Küng 1991:236-237).

Die vraag na die waarheid is vir Küng die een wat beantwoord moet word. Naas die teorie, is dit ook 'n praxis (Küng 1991:238). In 'n gesprek met ander godsdienste kan die Bybel nie die enigste bron-dokument vorm nie. Trouens, dit is in so 'n gesprek eintlik uit plek (Küng 1991:239). 'n Gesprek met ander godsdienste moet 'n inwaartse spiraal van drie fases hê: van die etiese na die religieuse en eers van hierdie algemeenhede af, na die Christelike geloof toe.

Wat vir Küng in enige godsdiens vooropstaan, is die menslikheid daarvan. Dit word ten diepste die kriterium van beoordeling (Küng 1991:244). Hieraan moet elke godsdiens gemeet word, en slaag die Christendom vir hom as die godsdiens par excellence.

Ten einde hierdie eksistensiale vertrekpunt te verdiskonteer, bedien Küng hom van die begrip paradigma. Paradigma is die grotere raamwerk of die konteks van 'n godsdiens of teks (Küng 1991:211). Op spoor van Thomas S Kuhn is dit 'n totale konstellasie van oortuigings, waardes en gedragspatrone. Hierbinne word dan subjektiewe en geleentheidskeuses (sinchronies) gemaak. Daarom is daar makro-, meso- en mikro-paradigmata. Dit lei dus na subjektiewe keuses.

Dit is ook die rede waarom ek nou Küng in hierdie kategorie van, nee, alle godsdienste aanbid nie dieselfde God nie, plaas. Laat ek Küng self verduidelik:

This one religion is for me the true religion for whose truth I can cite good reasons, that may possibly convince others. For me Christianity is the path that I take, the religion in which I believe I found the truth for my living and dying.

(Küng 1991:250)

Hierdie geloofskeuse, sê Küng, neem hy ook rasioneel en verantwoordelik op (Küng 1991:251). Daarom is dit sy keuse en sy oortuiging en sy antwoord. En binne hierdie oortuiging (lees: verhouding), is daar geen ander moontlikheid of Middellaar tot redding nie. 
Wolfhart Pannenberg is as moderne apologeet, sterk gekant teen 'n teologie soos die van Barth wat volgens hom in 'n esoterisme verval. Hy wil op rasionale gronde 'n gesprek met die wêreld voer en meen sodoende 'n sinvolle totaalprentjie van die werklikheid daar te stel. Eweneens is hy sterk gekant teen 'n eksistensiële reduksie van die geloof na die diepste innerlikheid van die wedergebore siel (Pannenberg 1975:31-56). Hy wil juis aantoon dat die Gees van God veral ook werksaam is in die geskiedenis, die biologie en die fisika as die lewe-gewende beginsel (vgl Gen 1:2; 2:7; 1 Kor 15:45; Ps 104; Pred 9:7; Spr 3:10). Bowendien openbaar God Homself ook in die geskiedenis van godsdienste.

Maar ten spyte van hierdie universele kontinuiteit, is daar ook juis die prinsipiële uniekheid in die Christendom geleë (Pannenberg 1979:291). Dit is vir Pannenberg 'n uitgemaakte saak dat Jesus Christus die sin en doel van die geskiedenis is. Alhoewel God Homself in die werklikheid, by name in die geskiedenis openbaar, doen Hy dit voistrek en ook prolepties in Jesus Christus. Die opstanding van Christus is dan die ontologiese daad van God vanuit die toekoms, wat sy Godheid onties bewys. Christus is die Openbaarder van die oneindige God (Pannenberg 1979:292). Alhoewel daar dus religieuse ervaring om die Christelike geloof kan wees, lê die Christendom in die sentrum. Dit is vir Pannenberg die Glaube und Wirklichkeit, die titel van een van sy boeke.

\section{ENKELE PRINSIPIëLE RIGLYNE VIR DIE PRAKTYK}

\subsection{Praktiese relevansie}

Die vraag wat deur die titel van hierdie referaat gestel is, het in die Suid-Afrikaanse konteks nuwe relevansie verkry met die destydse openingsgebede by KODESA I. Elk van die hoofgodsdienste in die land het geleentheid gehad om by wyse van 'n verteenwoordiger, vir die vergadering en die toekoms van die land te bid. Skerp kritiek is hierna vanuit Christelike oorde uitgespreek, selfs van die voormalige Staatspresident se kantoor af. Die gemiddelde argument wat gebruik was, is 1 Korintiërs 6:14 wat die gemeente waarsku om nie saam met die ongelowiges in dieselfde juk te trek nie.

'n Ander perspektief wat die saak aktueel maak, is die aandrang van ander godsdienste om ook lugtyd by die SAUK vir godsdiensprogramme te bekom. Hiervoor het die SAUK reeds goedkeuring verleen, en is tans besig met die praktiese implimentering daarvan. 


\subsection{Skriftuurlike verheldering}

Benewens die Bybelteks pas aangehaal, word daar ook na die Tien Gebooie verwys naamlik dat geen ander god geduld word nie en die gelowige nie met ander gode mag heul nie. Dit is nodig om nou enkele gedagtes oor die monoteïme in die $\mathrm{Ou}$ Testament te wissel.

Westermann sê in sy Theologie des Alten Testaments in Grundzügen, dat die enigheid van God nie altyd dieselfde in die Ou Testament verstaan is nie (Westermann 1978:25). Die een-wees van God is in die Ou Testament geen tydlose aangeleentheid nie. Hy onderskei derhalwe drie stadia:

- Die Eerste Gebod (Ex 20:3). Hier word hoegenaamd nie oor die bestaan of nie-bestaan van ander gode gepraat nie. Daar word aanvaar dat ander volke wel ander gode aanbid. In hierdie gebod gaan dit egter om die verbondsvolk wat in hulle verhouding met God, geen ander god kan of durf hê nie. Von Rad sluit hierby aan en sê dat hierdie gebod niks met monoteïme te doen het nie (Von Rad 1975:210). Ook hy sien 'n politeïme in die agtergrond raak.

* Die tweede fase is 'n fynere nuansering van eersgenoemde waar veral die enigheid, die uniekheid van Jahwe, sterk op die voorgrond tree. Vergelyk Deuteronomium 6:4, 'Luister, Israel, die Here is ons God, Hy is die enigste Here'. Die Ou Vertaling het nog gesê die Here is die 'enige Here'. Een godsdiens met een God kom hier aan die orde. Dit noem ons henoteïsme of ook monolatrie (Von $\operatorname{Rad} 1975: 211$ ). Lindblom verkies die woord dinamiese monoteïsme by die voor-eksiliese profete se godsdiensbeskouing (Lindblom 1973:333). Hierdie fase het ook voortgeduur tot die koningstydperk.

* Die derde stadium word met die profeet van Deutero-Jesaja aangetref. Jesaja 43:10 en 11 lees: 'Voor My was daar geen god nie, en na My sal daar ook nie een wees nie, Ek, Ek is die Here, buiten My is daar geen redder nie'. Hier tref ons vir eerste keer dus werklik monoteîme in die Bybel aan.

Die belangrike gevolgtrekking wat ons dus hieruit maak is dat 'n standpunt oor politeïme, henoteïme of monoteïme nie van deurslaggewende krag vir die onderhawige debat behoort te wees nie. Die saak word op 'n ander vlak besleg. Claus Westermann beklemtoon dat Israel nie oor sy God - of ander gode se bestaan al dan nie - geteoretiseer het nie, maar dat daar 'n konkrete verhouding tussen Jahwe en sy volk bestaan het van aksie en van reaksie, van woord en van antwoord. Die Tien Gebooie praat met óns as gelowiges en ons verhouding tot God en binne hierdie verhouding is daar nie plek vir 'n ander nie. 
By wyse van aksentuering wil ek net weer die personale verhouding tussen God en sy verbondsvolk benadruk as die Sitz im Leben van die Eerste Gebod. Dit sê niks oor ander mense en ander gode nie.

Die teks van die Nuwe Testament wat se dat die gelowiges nie met die ongelowiges in dieselfde juk moet trek nie, het die identiese Sitz im Leben. Dit gaan om 'n geloofsverhouding waar daar nie ruimte vir vreemde gode of gelowe is nie. Die oproep tot versoening is 'n afkeer teen die heidendom. Hy wat vrygespreek is, kan nie met ongeregtigheid voortgaan nie.

Die belangrikheid wat die persoonlike geloofsverhouding in die beantwoording van die onderhawige vraag speel, kom duidelik na vore in die volgende Nuwe Testamentiese teks:

En al is daar ook sogenaamde gode, of dit in die hemel en of dit op die aarde is, soos daar trouens baie is wat 'God' en baie wat 'Here' genoem word, is daar nogtans vir ons net een God: die Vader....

(1 Korintiërs 8:5-6)

Dit is egter nie uit sy plek om die Tweede Gebod ook hier ter sprake te maak nie. Die vraag of die Christen en die Jood en selfs ook die Moslem, dieselfde God aanbid, kan dalk hier tuishoort. Dit gaan dus dan nie om die vraag na wie die ware God is nie, maar om die vraag na die wyse van aanbidding van die ware God. Word God met ander woorde aanbid soos wat dit deur sy Woord aan ons gegee is?

\subsection{Die getalle-problematiek}

Suid-Afrika het die situasie dat $77.92 \%$ van die totale bevolking hulle as Christene aandui. Die Hindoeïme is $2.01 \%$, die Islam $1.40 \%$ en die Judaïme $0.42 \%$.

Nou hoor mens dikwels die argument dat die Christene in die meerderheid is en hulle voet vir 'n een-mens-een- stem godsdiensbedeling eenvoudig dwars moet neersit. Enige godsdiensbedeling moet dan op 'n pro rata-basis hanteer word. Dit is ironies dat hierdie suiwer getalle-argument vir baie mense op die godsdiensterrein moet geld, maar nie op die politieke terrein nie; of omgekeerd, op die politieke terrein maar nie op die godsdiensterrein nie.

Afgesien van die inkonsekwentheid van hierdie logika, het ek ook die teologiese vraag of die Christen hom durf beroep op 'n natuurlike situasie soos getalsterkte. Moet ons ons nie eerder laat lei deur 'n teologiese beginsel in hierdie verband nie? Die Christelike teologie se argument stoel tog op die herskepping en nie op die skepping nie! 


\subsection{Kerk en regering}

Dit is nodig om in hierdie debat die situasie raak te sien en in hierdie geval te onderskei tussen kerk en staat. KODESA is nie kerk nie. Dit is die ryk van die wêreld, om Luther se taal hiervoor te gebruik. Hierdeur word natuurlik nie gesê dat God of die gelowige niks met die staat te doen het nie. Inteendeel. Dit wil net sê dat God op 'n ander wyse deur die staat werksaam is as deur die kerk. Luther het ook in hierdie verband van die werk van die linker- en regterhand van God gepraat. Die wêreld se situasie vra dus uiteraard 'n ander hantering van godsdienste as in die kerk. In die kerk sou die Bybeltekste wat onder afdeling 4.2 behandel is, tuishoort.

Mens sou kon redeneer dat daar dalk glad nie by KODESA gebid moes word nie, maar dit is tog te verstane dat God deur gelowiges aangeroep word in situasies waar so baie vir ons op die spel is.

'n Argument wat ook gebruik kan word waarom die Christen tydens dieselfde byeenkoms te midde van ander godsdienste kan bid, is dat dit 'n missionêre karakter kan hê. Mens sou ook bloot die simboliese teenwoordigheid van die Christen by hierdie en derglike byeenkomste kon inreken. Dit is miskien wat gebeur wanneer 'n Christen-huisgesin in 'n restourant, te midde van ongelowiges en ander godsdiensaanhangers, voor ete sou bid.

Die punt is dus dat die konteks waarin gebid word, deurslaggewend vir teologiese interpretasie is.

\section{TER AFSLUTTING}

Samevattend lyk dit vir my belangrik om te onderstreep dat hierdie vraag van die opskrif, geen suiwer teoretiese of akademiese aangeleentheid is nie, maar wel 'n praktiese geloofswaarheid. Vir my is daar geen ander naam onder die hemel as Christus gegee nie en Hy is die Weg, die Waarheid en die Lewe. In hierdie verband praat Hendricus Berkhof ook van die 'ergernis van die absoluutheid' van Jesus Christus (Berkhof 1981:75). Of ons bely Christus en sy absoluutheid, of ons bely Hom heeltemal nie, sê hy. Vir hierdie belydenis het martelare met hulle lewens geboet. Die opstanding van Christus uit die dood is die basis van hierdie absoluutheid. En hieraan hou ons vas. Newbigin kan daarom ook sê dat die persoonlike oortuiging noodwendig verby die 'wat waar is vir my' moet beweeg, anders bly dit relatiwisme en is dit die eerste simptoom van die dood self (Newbegin 1989:22). Die waarheid is altyd meer en groter as die een wat daarin glo.

In die warmte van hierdie ek:U-verhouding is daar nie plek vir'n derde nie. Dit geskied in die praesenssfeer (Karl Heim) of dan die primêre werklikheid (Heinrich Ott). Hierdie ervaring is tegelyk ook'n stuk onsegbare waarheid. Taal en simboliek is maar die stotterende voorlopige pogings van verbalisering. En om op hierdie 
sekondêre werklikheid of dan die perfectumsfeer die saak met die godsdienste te besleg, is per se onmoontlik. Die tweede persoon-verhouding van ek:U het dan reeds oorgegaan in 'n derde persoon-verhouding van ek:dit (Heim 1949:192). En daar praat ons by mekaar verby.

In die inleidende paragraaf is die opmerking gemaak dat die vraag of die godsdienste dieselfde God aanbid, logies gesproke, slegs een van twee antwoorde kan hê, naamlik 'n ja of 'n nee. Intussen het dit duidelik geword dat hierdie vraag nie logies nie, maar eerder eksistensiaal hanteer behoort word. Dit beteken dan dat die vraag soos hy in die opskrif geformuleer is, eintlik nie beantwoord kán word nie. Dit is in 'n sekere sin dus 'n non-vraag. Die mens se Godskeuse is so 'n intens persoonlike saak dat dit nie klinies deur 'n buitestaander geverifieer kan word nie. Die verste wat ek dan kan gaan is om myself die vraag af te vra, of ék die ware God aanbid. Meer kan ek nie vra nie, maar ook nie minder nie.

\section{Literatuurverwysings}

Barth, K 1959. Die Lehre vom Wort Gottes: Prolegomena zur kirchlichen Dogmatik. Zweiter Band, in Die Kirchliche Dogmatik 1. Erster Teil. 4 Aufl. ZürichZollikon: Evangelischer Verlag.

Berkhof, H 1973. Christelijk Geloof: Een inleiding tot de Geloofsleer. Nijkerk: Callenbach.

— 1981. Bruggen en Brughoofden. Nijkerk: Callenbach.

Bonnhoeffer, D 1982. Christologie. Baarn: Ten Have.

Buitendag, J \& Van der Merwe, P J 1991. Die New Age beweging. Vereeniging: CUM.

Capra, F 1975. The Tao of physics: An exploration of the parallels between modern physics and Eastem mysticism. Glascow: William Collins.

Flannery, A P (ed) 1975. Documents of Vaticanum II: A new authorative translation of the Conciliar documents. Grand Rapids: Eerdmans.

Fohrer, G 1972. Theologische Grundstrukturen des Alten Testaments. Berlin: De Gruyter.

Galling, K (Hrsg) 1961. Die Religion in Geschichte und Gegenwart. Tübingen: Mohr.

Heim, K (Hrsg) 1976. Der Christliche Gottesglaube und die Naturwissenschaft, in Der evangelische Glaube und das Denken der Gegenwart, Vierte Band. Hamburg: Furche.

Henry, CF H 1973. Baker's dictionary of Christian ethics. Michigan: Grand Rapids. Joest, W 1984. Die Wirklichkeit Gottes, in Dogmatik. Band 1. Göttingen: Vandenhoeck \& Ruprecht. (UTB 1336.) 
Küng, H 1988. On being a Christian. Trd by Ed Quinn. Suffolk: HarperCollins.

- 1991. Theology for the third millennium: An ecumenical view. Tr by $\mathrm{P}$ Heinegg. London: HarperCollins.

Lindblom, J 1962. Prophecy in ancient Israel. Philadelphia: Fortress.

Newbigin, L 1989. The Gospel in a pluralist society. Grand Rapids: Eerdmans.

Ott, H 1972. Die Antwort des Glaubens: Systematische Theologie in 50 Artikeln. Stuttgart: Kreuz.

- 1978. Das Reden vom Unsagbaren: Die Frage nach Gott in unserer Zeit. Stuttgart: Kreuz.

Pannenberg, W 1979. Grundfragen systematischer Theologie. Göttingen: Vandenhoeck \& Ruprecht.

- 1975. Glaube und Wirklichkeit: Kleine Beiträge zum christlichen Denken. Munchen: Kaiser.

Rahner, K 1962. Schriften zur Theologie. Zürich: Benziger.

Von Rad, G 1975. Old Testament theology, II. London: SCM.

Westermann, C 1978. Theologie des Alten Testaments in Grundzügen. Göttingen: Vandenhoeck \& Ruprecht. (ATD 6.) 